\title{
Estimation of Constitutive Parameters Using a Loop Antenna
}

\author{
Lenler-Eriksen, Hans-Rudolph; Meincke, Peter; Jørgensen, E.
}

Published in:

Proceedings of 2nd International Workshop on Advanced GPR, The Netherlands

Publication date:

2003

Document Version

Publisher's PDF, also known as Version of record

Link back to DTU Orbit

Citation (APA):

Lenler-Eriksen, H-R., Meincke, P., \& Jørgensen, E. (2003). Estimation of Constitutive Parameters Using a Loop Antenna. In Proceedings of 2nd International Workshop on Advanced GPR, The Netherlands IEEE.

\section{General rights}

Copyright and moral rights for the publications made accessible in the public portal are retained by the authors and/or other copyright owners and it is a condition of accessing publications that users recognise and abide by the legal requirements associated with these rights.

- Users may download and print one copy of any publication from the public portal for the purpose of private study or research.

- You may not further distribute the material or use it for any profit-making activity or commercial gain

- You may freely distribute the URL identifying the publication in the public portal

If you believe that this document breaches copyright please contact us providing details, and we will remove access to the work immediately and investigate your claim. 


\title{
ESTIMATION OF CONSTITUTIVE PARAMETERS USING A LOOP ANTENNA
}

\author{
H.R. Lenler-Eriksen, P. Meincke, and E. Jørgensen \\ Ørsted.DTU \\ Electromagnetic Systems, Ørsteds plads, Bldg. 348, Technical University of Denmark \\ DK-2800 Kgs. Lyngby, Denmark \\ hle@oersted.dtu.dk pme@oersted.dtu.dk ej@oersted.dtu.dk
}

\begin{abstract}
A method for estimating the constitutive parameters of soil using a loop antenna is proposed. The method is based on comparing measured and numerically calculated input admittances for the loop.
\end{abstract}

Key words: Constitutive parameters, loop antenna, input admittance.

\section{INTRODUCTION}

Measurement facilities for ground penetrating radar (GPR) antennas have been developed to perform tests in controlled environments [1], [2], [3]. In these facilities a probe antenna is buried in a box with soil and the GPR antenna under test is scanned over the surface of the soil. The field radiated by the GPR antenna is measured using the probe. Measurements are performed in the time domain using short impulses. As described in [4] it is necessary to know the plane-wave (PW) receiving spectrum of the probe to obtain an accurate $\mathrm{PW}$ transmitting spectrum of the GPR antenna. The PW receiving spectrum is obtained through knowledge of the current distribution on the probe. The current distribution depends on the constitutive parameters (CP's) of the soil in the vicinity of the probe. The CP's comprise the permittivity $\varepsilon$, permeability $\mu$, and conductivity $\sigma_{e}$. The permittivity is written as

$$
\varepsilon=\varepsilon^{\prime}-j \varepsilon^{\prime \prime}
$$

where $\varepsilon^{\prime}$ and $\varepsilon^{\prime \prime}$ are real and positive quantities (the time factor $e^{j \omega t}$ is used). It is assumed that the conductivity $\sigma_{e}$, the dielectric losses $\varepsilon^{\prime \prime}$ and the real part of the permittivity $\varepsilon^{\prime}$ are independent of the frequency and that the permeability $\mu$ is equal to the vacuum permeability $\mu_{0}$. It is desirable that the probe itself is used for an estimation of the CP's of the soil. In this paper we use the input admittance of the probe antenna to estimate the CP's for the case in which the probe antenna is a circular loop [1], [5], [6]. The CP's are estimated by comparing the input admittance for the actual probe and the input admittance for a theoretical model of the probe. This theoretical model consists of a perfect electric conductor (PEC) loop in a homogeneous soil in parallel with a capacitor and a resistor. The PEC loop is analyzed with the method of moments (MoM). The theoretical input admittance is thus the sum of the input admittances for the PEC loop, the capacitor, and the resistor. The input admittance of the PEC loop is calculated for a range of frequencies and conductivities of the soil. The calculations are done for a fixed permittivity, and input admittances for other permittivities can be found by an appropriate scaling. The CP's of the theoretical model are assumed to correspond to the CP's of the soil in the vicinity of the loop when the theoretical and measured admittances are identical.

\section{THE LOOP AND THE THEORETICAL MODEL}

The loop antenna used for measurements is constructed in the same way as described in [5], [6]. As shown in Figure 1 the loop consists of a bended UT-141A semi-rigid cable with a minimum inside bending radius of $6.35 \mathrm{~mm}$.

The PEC loop is modeled as a PEC torus with the radii $a=1.75 \mathrm{~mm}$ and $b=17.13 \mathrm{~mm}$, see Figure 2. The mesh in the MoM calculations is shown in Figure 3 [7]. As shown in Figure 4 the excitation cut in the outer conductor is simulated as two PEC surfaces connected through a wire. A voltage generator is placed in the middle of the wire for excitation of the PEC loop. The input admittance of the loop calculated using MoM is called $Y_{M \circ M}$.

The theoretical model consists of a capacitor and a resistor in parallel with the PEC loop, see Figure 5. The 


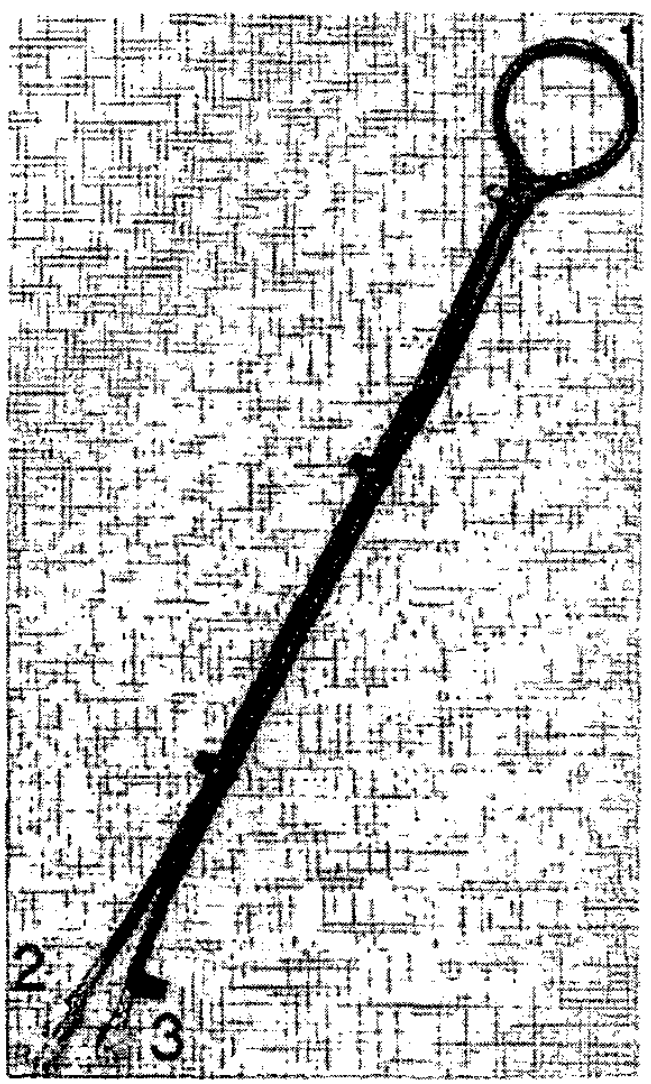

Figure 1: The constructed loop antenna is made of a semi-rigid cable. 1) The excitation cut in the outer conductor is covered by epoxy. The width of the cut is $0.50 \mathrm{~mm}$. 2) Termination using $50 \Omega$ load. 3) Input port.

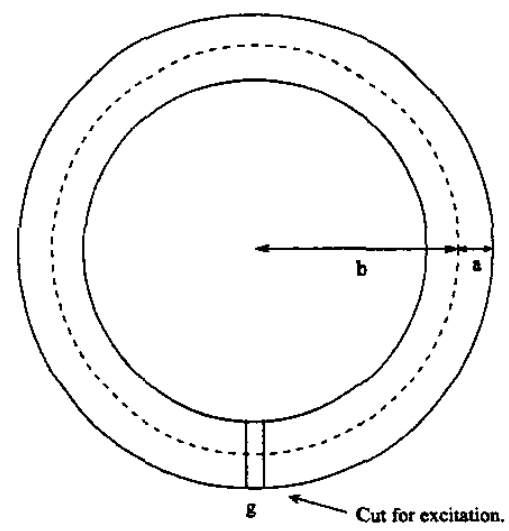

Figure 2: Definitions of the radii $a, b$ and the width $g=$ $0.5 \mathrm{~mm}$ of the excitation cut in the torus.

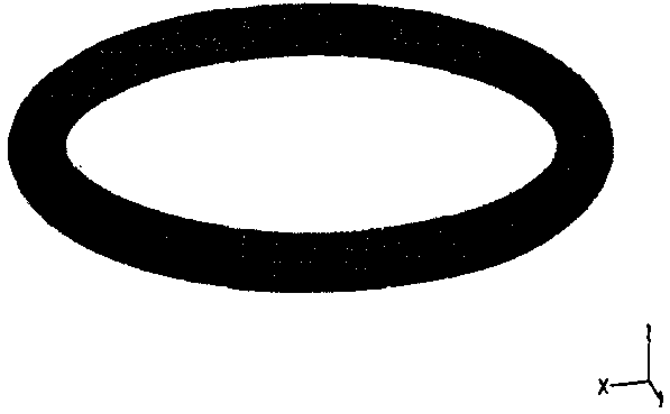

Figure 3: The mesh used to analyze the PEC loop using MoM.

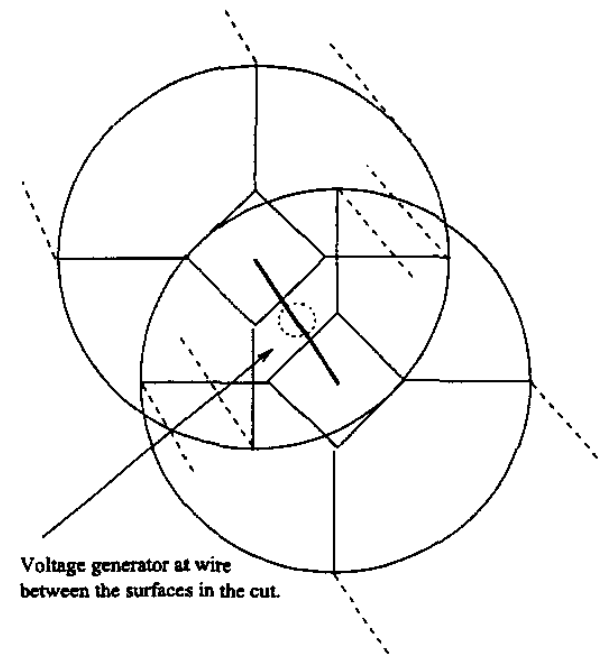

Figure 4: The mesh in the excitation cut. The two PEC surfaces are connected through a wire with a radius of $0.105 \mathrm{~mm}$.

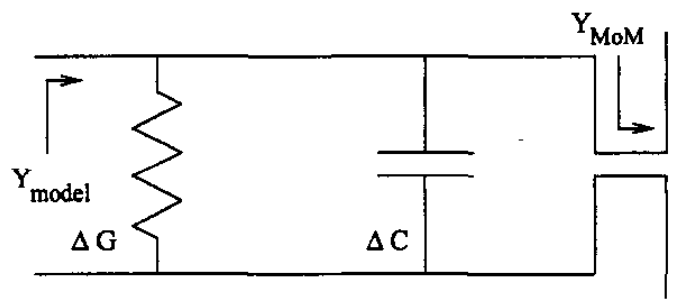

Figure 5: The theoretical model consists of a PEC loop in parallel with a capacitor and a resistor. 
input admittance $Y_{\text {model }}$ of the model can be written as

$$
\begin{aligned}
Y_{\text {model }}\left(\omega, \varepsilon^{\prime}, \sigma_{e f f}\right)= & Y_{M o M}\left(\omega, \varepsilon^{\prime}, \sigma_{e f f}\right) \\
& +\Delta G+j \omega \Delta C,
\end{aligned}
$$

where the effective conductivity is defined as

$$
\sigma_{e f f}=\omega \varepsilon^{\prime \prime}+\sigma_{e} .
$$

The parameters in the model for the physical antenna are therefore the differences $\Delta G, \Delta C$, and the CP's $\varepsilon^{\prime}, \varepsilon^{\prime \prime}$, and $\sigma_{e}$. These parameters can be estimated by minimizing an error function.

The input admittance $Y_{M o M}\left(\omega, \varepsilon^{\prime}, \sigma_{e f f}\right)$ is found using method of moments for a relative permittivity $\varepsilon_{r}^{\prime}=8$ over a range of frequencies from $10 \mathrm{MHz}$ to $6 \mathrm{GHz}$ and a range of conductivities from 0 to $1 \mathrm{~S} / \mathrm{m}$. As shown in the next section, input admittances for other permittivities $\varepsilon^{\prime}$ can be found by an appropriate scaling.

\section{DETERMINING INPUT ADMTTTANCES OF THE PEC LOOP FOR OTHER CP'S}

In this section it will be shown how the input admittance $Y_{M o M}$ for the PEC loop can be determined for other frequencies and CP's than those calculated in the previous section. The input admittance $Y_{M o M}$ depends on the angular frequency $\omega$ and the CP's of the soil, that is, $Y_{M \circ M}=Y_{M \circ M}\left(\omega, \varepsilon^{\prime}, \sigma_{e f f}\right)$. Denote by $Y_{1}$ the input admittance for the case in which the angular frequency equals $\omega_{1}$ and the CP's are $\varepsilon_{1}^{\prime}$ and $\sigma_{e f f, 1}$, that is, $Y_{1}=Y_{M \circ M}\left(\omega_{1}, \varepsilon_{1}^{\prime}, \sigma_{e f f, 1}\right)$. Consider now another case in which the permittivity is $\varepsilon_{2}^{\prime}$. The input admittance $Y_{2}=Y_{M o M}\left(\omega_{2}, \varepsilon_{2}^{\prime}, \sigma_{e f f, 2}\right)$, with $\omega_{2}$ and $\sigma_{e f f, 2}$ being unknown at the moment, is desired. To this end, introduce the normalized position vector $\mathbf{r}_{N}=\omega \sqrt{\mu_{0} \varepsilon^{7}} \mathbf{r}$, with $\mathbf{r}$ being the unnormalized position vector, and consider the normalized version of Maxwell's curl equations [8],

$$
\begin{aligned}
& \nabla_{N} \times \mathbf{E}_{N}=-j \mathbf{H}_{N}, \\
& \nabla_{N} \times \mathbf{H}_{N}=j(1-j \tan \delta) \mathbf{E}_{N},
\end{aligned}
$$

where $\nabla_{N}$ acts upon the normalized coordinates and the normalized fields $\mathbf{E}_{N}$ and $\mathbf{H}_{N}$ are

$$
\begin{aligned}
\mathbf{E}_{N} & =\sqrt{\sqrt{\frac{\varepsilon^{\prime}}{\mu_{0}}}} \mathbf{E}, \\
\mathbf{H}_{N} & =\sqrt{\sqrt{\frac{\mu_{0}}{\varepsilon^{\prime}}}} \mathbf{H} .
\end{aligned}
$$

Moreover, the loss tangent is given by

$$
\tan \delta=\frac{\sigma_{e f f}}{\omega \varepsilon^{\prime}} .
$$

It is seen that if the loss tangent $\tan \delta$ and the normalized position vector $\mathbf{r}_{N}$ are identical for two cases, the normalized fields are also identical. When this is the case, it can also be shown that the normalized input admittances, defined as $\sqrt{\frac{\mu_{0}}{\varepsilon^{\prime}}} Y_{M o M}$, are identical for the two cases. Hence, the desired $Y_{2}=Y_{M \circ M}\left(\omega_{2}, \varepsilon_{2}^{\prime}, \sigma_{e f f, 2}\right)$ can be found from $Y_{1}$ when $\omega_{2}=\sqrt{\frac{\varepsilon_{1}^{\prime}}{\varepsilon_{2}^{\prime}}} \omega_{1}$ and $\sigma_{\text {eff }, 2}=$ $\sqrt{\frac{\varepsilon_{2}^{\prime}}{\varepsilon_{1}^{\prime}}} \sigma_{e f f, 1}$, and the result is

$$
Y_{2}=\sqrt{\frac{\varepsilon_{2}^{\prime}}{\varepsilon_{1}^{\prime}}} Y_{1}
$$

\section{COMPARING MEASURED AND THEORETI- CAL ADMITTANCES}

The network analyzer is calibrated such that the reference plane of the measured S-parameter $S_{11, c n}$ is located at the input port of the loop antenna. The S-parameter $S_{11, a}$ at the excitation cut can be found as

$$
S_{11, a}\left(\omega, \varepsilon^{\prime}, \sigma_{e f f}, \Delta t\right)=S_{11, c n}\left(\omega, \varepsilon^{\prime}, \sigma_{e f f}\right) e^{j \omega \Delta t},
$$

where $\Delta t$ is twice the distance in time between the connector and the cut. The input admittance of the loop can be found as

$$
Y_{a}\left(\omega, \varepsilon^{\prime}, \sigma_{e f f}, \Delta t\right)=Y_{0} \frac{1-S_{11, a}\left(\omega, \varepsilon^{\prime}, \sigma_{e f f}, \Delta t\right)}{2 S_{11, a}\left(\omega, \varepsilon^{\prime}, \sigma_{e f f}, \Delta t\right)},
$$

where $Y_{0}$ is the characteristic admittance of the semirigid cable. To determine the unknown parameters $\varepsilon^{\prime}$, $\varepsilon^{\prime \prime}, \sigma_{e}, \Delta G$, and $\Delta t$ we define the error function as

$$
\begin{aligned}
& \varsigma\left(\varepsilon^{\prime}, \sigma_{e f f}, \Delta G, \Delta t\right) \equiv \\
& \int\left|\frac{\operatorname{Re}\left[Y_{a}\left(\omega, \varepsilon^{\prime}, \sigma_{e f f}, \Delta t\right)-Y_{M o M}\left(\omega, \varepsilon^{\prime}, \sigma_{e f f}\right)-\Delta G\right]}{\operatorname{Re}\left[Y_{a}\left(\omega, \varepsilon^{\prime}, \sigma_{e f f}, \Delta t\right)\right]}\right| d \omega .
\end{aligned}
$$

It is assumed that the permittivity $\varepsilon^{\prime}$ and conductivity $\sigma_{e f f}$ correspond to the CP's of the soil in vicinity of the loop antenna when the error function $\varsigma\left(\varepsilon^{\prime}, \sigma_{e f f}, \Delta G, \Delta t\right)$ is minimized.

\section{FINDING THE TIME DELAY}

The time delay $\Delta t$ is estimated using a measurement in air. The CP's are known in air and it is therefore only necessary to estimate the differences $\Delta C$ and $\Delta G$ besides the time delay $\Delta t$, see Table 1 . The loop antenna is kept at a distance of $30 \mathrm{~cm}$ from other objects during the measurement in air. The error function $\varsigma$ is plotted as a function of $\Delta t$ in Figure 6 for $\Delta C=0.234 \mathrm{pF}$ 
and $\Delta G=0.27 \mathrm{mS}$. It is seen that the global minimum is well-defined. In Figure 7 the difference of the input admittances $Y_{a}-Y_{M o M}$ is plotted as a function of frequency. Linear relations between the real and imaginary parts of $Y_{a}-Y_{M o M}$ and frequency are expected. The linear relation between the imaginary part of $Y_{a}-Y_{M o M}$ and frequency is considered as a verification of the model, since only the real part is used in the error function $\varsigma$.

\begin{tabular}{|l|l|}
\hline Range of frequencies $f(\mathrm{MHz})$ & {$[178 ; 2495]$} \\
\hline Search range for $\Delta t(\mathrm{~ns})$ & {$[2.640 ; 3.040]$} \\
\hline Range of conductivities $\Delta G(\mathrm{mS})$ & {$[-1 ; 1]$} \\
\hline Rel. permittivity $\varepsilon_{r}^{\prime}$ & 1 \\
\hline Conductivity $\sigma_{e f f}$ & 0 \\
\hline Estimations: & \\
\hline Diff. in capacitance $\Delta C(\mathrm{pF})$ & 0.234 \\
\hline Diff. in conductance $\Delta G(\mathrm{mS})$ & 0.27 \\
\hline Time delay $\Delta t(\mathrm{~ns})$ & 2.894 \\
\hline
\end{tabular}

Table 1: Estimation of time delay $\Delta t$.

\section{ESTIMATING CP'S OF SOIL}

After the estimation of the time delay $\Delta t$, an estimation of CP's in soil is performed, see Table 2. The loop antenna is buried in homogeneous and dry soil in a depth of $15 \mathrm{~cm}$. The error function $\varsigma$ is plotted as a function of the relative permittivity $\varepsilon_{r}^{\prime}$ and the conductivity $\sigma_{e}$ for $\varepsilon^{\prime \prime}=1.1 \mathrm{pF} / \mathrm{m}$ in Figure 8 . It is seen that the global minimum $\left(\varepsilon_{r}^{\prime}, \sigma_{e}\right)=(2.8,15 \mathrm{mS} / \mathrm{m})$ is well-defined for $\varepsilon^{\prime \prime}=1.1 \mathrm{pF} / \mathrm{m}$ and the considered range. To verify the result the measured and theoretical input admittances are plotted as a function of frequency in Figure 9. The measured input admittances are in agreement with the theoretical input admittances.

\section{SUMMARY}

A method for estimation of CP's has been developed. The method is based on a comparison between measured input admittances and calculated input admittances of a theoretical model. CP's are estimated by minimizing an error function such that measured and theoretical input admittances are identical. The method has been used for estimation of CP's for dry soil. The method is applicable in measurement facilities for GPR antennas where the loop antenna is used as a probe.

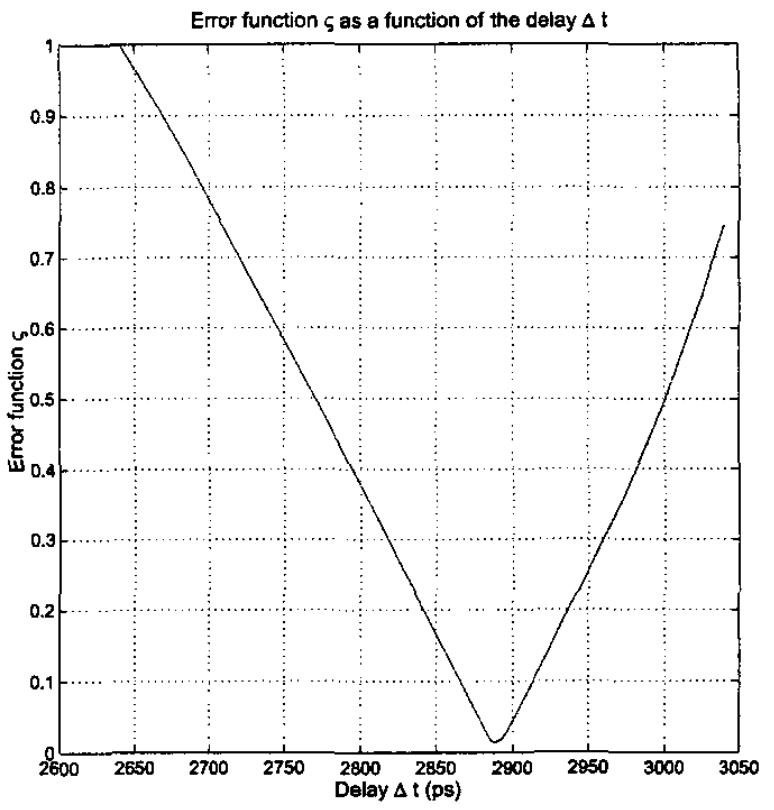

Figure 6: The error function $\varsigma$ has been normalized such that the maximum value is 1 . The minimum value of the error function $\varsigma$ occurs at the time delay $\Delta t=2.894 \mathrm{~ns}$.

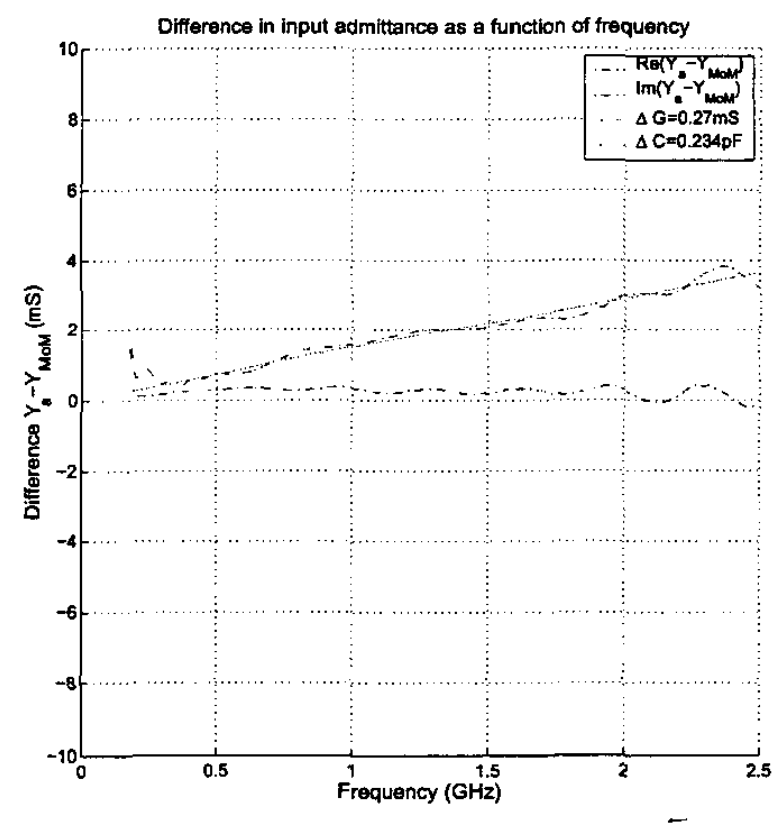

Figure 7: The difference in the admittances are given by $Y_{a}-Y_{M o M}=0.27 \mathrm{mS}+j \omega 0.234 \mathrm{pF}$. 


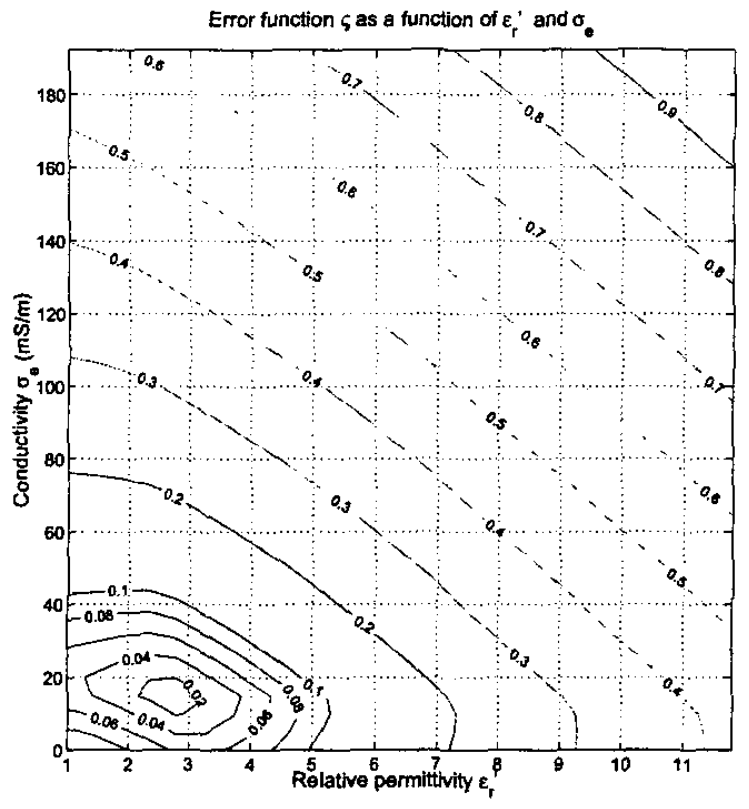

Figure 8: The error function has been normalized such that the maximum value is 1 . The minimum value of the error function occurs at $\left(\varepsilon_{r}^{\prime}, \sigma_{e}\right)=(2.8,15 \mathrm{mS} / \mathrm{m})$.

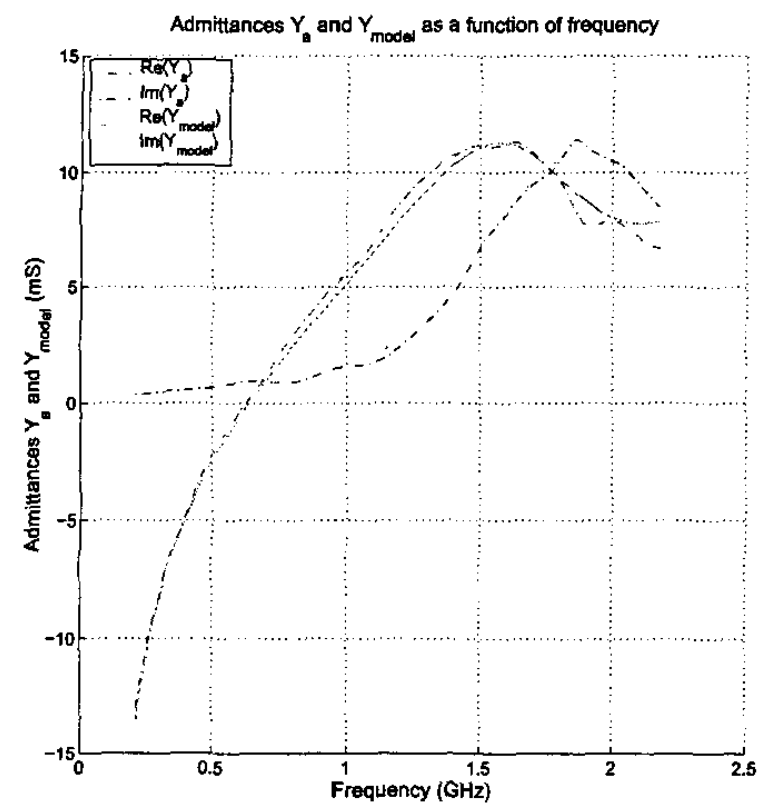

Figure 9: The measured input admittance $Y_{a}$ should be equal to the theoretical input admittance $Y_{\text {model }}$.

\begin{tabular}{|l|l|}
\hline Range of frequencies $f(\mathrm{MHz})$ & {$[210 ; 2180]$} \\
\hline Time delay $\Delta t(\mathrm{~ns})$ & 2.894 \\
\hline Range of conductivities $\Delta G(\mathrm{mS})$ & {$[-10 ; 5]$} \\
\hline Range of rel. permittivities $\varepsilon_{r}^{\prime}$ & {$[1 ; 21.7]$} \\
\hline Range of dielectric losses $\varepsilon^{\prime \prime}(\mathrm{pF} / \mathrm{m})$ & {$[0 ; 15.7]$} \\
\hline Range of conductivities $\sigma_{e}(\mathrm{mS} / \mathrm{m})$ & {$[0 ; 493]$} \\
\hline Estimations: & \\
\hline Diff. in capacitance $\Delta C(\mathrm{pF})$ & -0.2 \\
\hline Diff. in conductance $\Delta G(\mathrm{mS})$ & -0.5 \\
\hline Rel. permittivity $\varepsilon_{r}^{\prime}$ & 2.8 \\
\hline Dielectric losses $\varepsilon^{\prime \prime}(\mathrm{pF} / \mathrm{m})$ & 1.1 \\
\hline Conductivity $\sigma_{e}(\mathrm{mS} / \mathrm{m})$ & 15 \\
\hline
\end{tabular}

Table 2: Estimation of CP's in soil.

\section{REFERENCES}

[1] R.V. de Jongh, A.G. Yarovoy, L. P. Ligthart, I.V. Kaploun, and A.D. Schukin, "Design and analysis of new GPR antenna concepts," in Proc. of GPR'98, 7th International Conference on Ground Penetrating Radar, USA, May 1998, pp. 81-86.

[2] R.V. de Jongh, A.G. Yarovoy, and L.P. Ligthart, "Experimental set-up for measurement of GPR antenna radiation patterns," in Proc. of the 28th European Microwave Conference, Amsterdam, The Netherlands, Oct. 1998 , pp. 539-543.

[3] A.G. Yarovoy, P.J. Aubry, and L.P. Ligthart, "GPR Antenna Measurements in Time Domain," in Conference Proc. on CD-ROM, Millennium Conference on Antennas and Propagation, Davos, Switzerland, Apr. 2000.

[4] P. Meincke and T.B. Hansen, "Plane-wave characterization of an antenna close to a planar interface," Submitted to IEEE Transactions on Geoscience and Remote Sensing.

[5] J.J. Goedbloed, Electromagnetic compatibility, pp. 40-44, Prentice Hall, New York, N.Y., 1992.

[6] R.V. de Jongh and A.G. Yarovoy, "Ultra-wideband sensor for electromagnetic field measurements in time domain," in Electronic Letters, Sept. 2000, pp. 1679 1680.

[7] E. Jørgensen, J. L. Volakis, P. Meincke, and O. Breinbjerg, "Higher-order hierarchical legendre basis functions for electromagnetic modeling," Feb. 2003, Submitted to IEEE Transactions on Antennas and Propagation.

[8] R. W. P. King and G. S. Smith, Antennas in Matter, pp. 727-731, The MIT Press, USA, 1981. 